\title{
EL TRABAJO DE LA MUJER EN EL SIGLO XXI. LA EXPERIENCIA DE LA MUJER EN EL MUNDO LABORAL
}

Nieto-Morales, C; Vázquez Fernández, M. J; Nieto-Cabrera, M. E. (2020) EL TRABAJO DE LA MUJER EN EL SIGLO XXI. La experiencia de la mujer en el mundo laboral. Dykinsón. Madrid. Libro electrónico pp 690

El libro "EL TRABAJO DE LA MUJER EN EL SIGLO XXI. La experiencia de la mujer en el mundo laboral" que ha sido compilados por las profesoras: Concepción Nieto-Morales, M. Josefa Vázquez Fernández y M. Elena NietoCabrera, consta de prólogo, 36 capítulos y una reflexión final a modo de conclusión.

El libro ha sido prologado por la Ilma. Sra. Coordinadora Fiscal del Tribunal Superior de Andalucía Dña. Ana María Hermosa Martínez, mujer trabajadora, gran profesional y jurista, conocedora de las dificultades que presenta conciliar vida familiar: ser madre y mujer trabajadora; al igual que la gran mayoría de las profesionales que han participado en el libro como coautoras.

El primer capítulo La importancia de la formación en el desempeño profesional, cuyas autoras son: Dña. María Elena Nieto-Cabrera, Dña. Lourdes Nieto Cabrera y la Dra. Concepción Nieto-Morales, sirve de introducción y concienciación respecto a la importancia de la formación para el desempeño de cualquier profesión, haciendo especial hincapié en el mérito y la capacidad en un mundo globalizado, donde no solo se compite con profesionales de la misma localidad, Comunidad Autónoma o país, sino de cualquier ubicación del mundo. Se analiza desde la globalización a la localización.

En general si no nos atañe personalmente, el mundo laboral está tan especializado que desde el punto de vista profesional suele ser desconocido y especialmente el ámbito de la Judicatura. El segundo capítulo: El día que cambio mi vida. La mujer Fiscal en España. Cuya autora es la Ilma. Sra. Dña. Susana Hernando Ramos, Fiscal de la Fiscalía de Menores y Familia de la Fiscalía de Sevilla, relata su experiencia con unas oposiciones muy complicadas y como cuando aprobó, fue el día más feliz de su vida hasta ese momento, y plasma una experiencia laboral muy gratificante, en el desempeño de su trabajo con gran profesionalidad. 
El tercer capítulo El hábito no hace al monje, ni la toga al abogado. Por la lucha y defensa de los derechos. la mujer en la abogacía. Cuyas autoras son la abogada coordinadora del turno de oficio de Violencia de Genero del Ilustre Colegio de Abogados de Sevilla Dña. Amalia Calderón y la socióloga Dña. Amalia M. Calderón. El capítulo realiza un recorrido sobre las pioneras de la abogacía y concluye con la trayectoria profesional de Dña. Amalia Calderón.

Ha sido todo un reto el capítulo cuatro, sobre la mujer en el Cuerpo de la Guardia Civil, concluyendo en el capítulo: Inapelables al desaliento. La mujer en el Cuerpo de la Guardia Civil, cuya autora es la Teniente de la Guardia Civil, Dña. María Isabel García Núñez, perteneciente al Gabinete Técnico del Área de Mujeres e Igualdad de la Guardia Civil en Madrid. La autora analiza un trabajo tradicionalmente desarrollado por hombres, donde la incursión profesional de la mujer se va aceptando, y a medida que va cambiando la sociedad se hace la mujer más visible.

Al igual que el capítulo anterior, el capítulo número cinco dedicado al cuerpo Nacional de la Policía, titulado: Una decisión clara y firme sobre la elección del futuro. La mujer en la Policía Nacional, cuya autora Dña. Ana Cambón Blanco, que es Inspectora Jefa de Policía Nacional, Jefa de la Brigada Móvil-Policía en el Transporte de Sevilla y Punto de Contacto en Andalucía Occidental de la Oficina Nacional para la Igualdad de Género en la Policía Nacional. Relata la autora la trayectoria del cuerpo de la Policía Nacional y su propia experiencia profesional en dicho cuerpo que -al igual que la Guardia Civil- ha sido hasta hace un par de décadas una profesión netamente masculina.

El capítulo seis dedicado a la mujer en la política y titulado La participación de la mujer en la gobernanza Política, cuya autora es la Exma. Sra. Dña. Teresa Jiménez Becerril, cuya incursión en política se debió al asesinato de su hermano por la banda terrorista ETA. El capítulo hace una magnifica semblanza de su relación fraternal. Dña. Teresa ha sido y es una firme defensora de las víctimas del terrorismo desde hace años, primero en el Parlamento Europeo y actualmente desde el Congreso de los Diputados de España, como parlamentaria a nivel nacional.

La universidad ha sido y es formación y cultura, llegando al culmen de la conformación académica en el grado de doctor. En el capítulo siete, de este libro titulado: Mujeres en la universidad española del siglo XXI: De las pioneras a nuestros días, cuya autora es la Dra. M. del Rosario Carmona Luque, profesora contratada doctora de la Universidad Pablo de Olavide, realiza una trayectoria de la universidad y desde las primeras mujeres universitarias hasta nuestros días.

El capítulo ocho, en consonancia con el anterior dedicado a la mujer y la universidad, la investigación es un campo que forma parte esencial de la universidad y el capítulo Construyendo un espacio propio en la comunidad científica. Mujer y ciencia, cuya autora es la Dra. Mercedes Díez Rodríguez, expone el trabajo de la mujer en el mundo de la investigación, un mundo muy desconocido para quienes no forman parte de la universidad y grandes corporaciones.

Actualmente se habla constantemente de emprendimiento, no podía faltar el capítulo nueve dedicado a la mujer empresaria y titulado: El emprendimiento vocacional como profesión. Los desafíos del día a 
día por trabajar y mantener la empresa con perspectiva de futuro. La mujer en la clínica de Podología, cuya autora es Dña. Rosario Jiménez Caro, que regenta una clínica de Podología, plasma el absoluto calvario que en ocasiones lleva implícito ser trabajador autónomo, en un amplio espectro de circunstancias.

El capítulo diez, dedicado a la mujer en la dirección y gestión titulado: Rompiendo el techo de cristal. La mujer en la gestión y dirección empresarial, cuya autora es Dña. Mercedes Pérez Verdugo, refleja una trayectoria de trabajo y gestión muy importante en el desempeño profesional, donde aún son pocas las mujeres que ejercen el cargo de directoras.

Aún existen profesiones, como se ha visto, donde los hombres son mayoría, es lo que ocurre en el capítulo once dedicado a la ingeniería y titulado: La mujer en la ingeniería: Percepción de cambio vs cambio de percepción, de la Pfra. de la facultad de ingenieros de Sevilla, Dña. Amalia Santana Hidalgo, que fue la Primera mujer docente e investigadora en el Departamento de Ingeniería Energética de la Universidad de Sevilla.

El capítulo doce, está dedicado a la profesión sanitaria, profesión fuertemente femenina en el ámbito de enfermeria y algo menos respecto a la medicina. El capítulo titulado La profesión sanitaria. ¿Vocación o profesión? Medicina y enfermeria. La Dra. Reyes Baena Luna realiza una trayectoria personal por su gran vocación que es la medicina y Dña. Lourdes Nieto-Cabrera profundiza en una trayectoria amplia respecto a la enfermería, sin dejar la formación, finalizando el grado en Odontología. Las profesiones sanitarias suelen ser fuertemente profesiones vocacionales.

La autora del capítulo trece, Dña. María del Carmen Guajardo-Fajardo Herrera, titulado: Psicología; una ciencia en expansión. La mujer en el ámbito de la psicología. Considera que la mujer en el ámbito de la psicología ha tenido implicación desde los comienzos de la profesión, siendo una disciplina atractiva para las mujeres.

En el capítulo catorce, titulado La igualdad se vende en farmacia, sobre la mujer farmacéutica y cuya autora es Dña. Gloria Calzado González. La autora concluye que "a pesar de la corta trayectoria reconocida de la mujer en la farmacia, parece increíble que en la actualidad el 70\% de colegiados seamos farmacéuticas. Debemos valorar el esfuerzo de las pioneras que apostaron por formarse en la sanidad, la investigación, el paciente y su tratamiento". También pone de manifiesto que la profesión se encuentra en auge a todos los niveles.

Dña. Eva Diaz Alférez es la autora del capítulo quince, titulado: La veterinaria dedicada a la medicina de los pequeños animales. La autora pone de manifiesto que, la veterinaria quizá, sea de las profesiones más tardías en las que se ha tenido acceso por parte del sexo femenino, siendo una profesión. copada mayoritariamente por hombres.

En el capítulo dieciséis, Dña. María José León Diaz autora del capítulo: La promoción de las personas con necesidad de oportunidades. La mujer en el Trabajo Social. La autora manifiesta que "la profesión de Trabajo Social, es una de las profesiones más feminizadas que existen, porque en su ejercicio reúne básicamente las tareas de cuidado y protección que se les han asignado solo por cuestión de género y que seguimos teniendo asignadas en la actualidad". 
El capítulo diecisiete, titulado: La Fuerza del Coraje. Un ejemplo de cómo enfrentarse a la vida superando barreras, retos $y$ discriminaciones. Mujer y discapacidad. Cuya autora es Dña. Isabel Viruet García, presidenta del Consejo Territorial de la ONCE en Andalucía, Ceuta y Melilla. Es también secretaria general del CERMI (Comité Español de Representantes de Personas con Discapacidad) en Andalucía y de la Mesa del Tercer Sector en Andalucía. Describe su trayectoria personal y laboral a pesar de las dificultades personales en la "búsqueda permanente por la inclusión".

La profesora Dra. María José Vázquez Fernández, ha contribuido con el capítulo número dieciocho, titulado: La atención a las personas en situación de dependencia: Feminización del cuidado, Orígenes y consecuencias. Este capítulo, a través de varias entrevistas a profesionales del cuidado refleja las circunstancias laborales y feminización de la profesión.

El capítulo número diecinueve, titulado: La reivindicación de derechos: Lucha con objetivos. La mujer sindicalista, cuyas autoras Dña. María Elena Nieto-Cabrera y la Dra. Concepcion Nieto-Morales, ponen de manifiesto la trayectoria de luchas y reivindicaciones para la consecución de derechos y el detrimento que vive actualmente el sindicalismo.

El libro es diverso, en el capítulo número veinte cuya autora es una mujer que se autodefine y ha titulado del mismo modo el capítulo: Feminista de izquierda de los 70, andaluza/ catalana. Profesionalmente: gestión socioeconómica. De la Pfra. Ana Almirón Mengíbar. El capítulo realiza un recorrido de la historia de vida de la protagonista donde se refleja también de forma paralela la historia de España.

El capítulo número veintiuno, titulado: Poder, mujer y comunicación. El trabajo de la mujer como escritora. Cuya autora es la Dra. Cristina Martin-Jiménez, que es Doctora en Ciencias de la Comunicación. Escritora, periodista y científica, autora de varios best seller traducidos a diferentes idiomas. Sitúa el énfasis en "ser mujer para comprenderlo. Ser mujer para contarlo. Y recibir los ataques más enconados de la bestia, precisamente, por ser mujer".

La mujer y el deporte se ubica en el capítulo veintidós, titulado: El objetivo no es solo competir, sino ganar. deporte: ¿cuestión de género? La mujer deportista. Cuyas autoras son Dña. María Elena Nieto-Cabrera y la deportista que cosecha una importante trayectoria de triunfos en el atletismo, Dña. Alicia Lozano Royano. El capítulo expone las diferencias entre sexos que marcadamente minusvaloran el triunfo de la mujer, diferenciándola del varón en los premios percibidos.

El capítulo número veintitrés, titulado: Tú me preguntas: ¿qué es la comunicación? y yo te respondo: Transmitir desde distintas perspectivas su esencia. Cuya autora es la periodista Dña. Laura Robles Ortega. En sus conclusiones refleja "el camino ha sido largo, duro y difícil, pero al final se ha conseguido que poco a poco que el sexo femenino alce la voz y se le escuche y, ante todo, que pueda informar, liderar y formar a más mujeres a seguir siendo valientes a la hora de desempeñar una profesión "de riesgo" como ésta.

La profesión de guía turístico hace pocas décadas que se conoce, y se refleja en capitulo veinticuatro, titulado: Otras formas de vivir y conocer. La 
mujer en el trabajo turístico. Cuya autora es Dña. Carmen Petauer, que desarrolla su trabajo en Austria. Nacida en Alemania, criada en España, regresó a Alemania, casada con un austriaco y residente en Austria, luchando no solo por abrirse camino en la profesión como mujer sino como alguien no nativo que implica doble hándicap.

El capítulo número veinticinco, titulado: La arquitectura no es cuestión de género. Cuyas autoras son Dña. Ángela Bersabé De la Rosa y Dña. Ma Dolores Mora Bueno, dos arquitectas que han vivido la discriminación de ser mujer en un mundo laboral, plenamente desarrollado por hombres. Refleja las dificultades laborales, incrementadas por el hecho de ser mujer.

Dña. Lourdes Soriano Arias, maestra ya retirada y autora del capítulo número veintiséis, titulado: Experiencia de una utopía educativa temporal. Mi experiencia como mujer y maestra. Relata en el capítulo las dificultades que ha vivido el mundo de la enseñanza en España. La profesión de maestra ha sido desempeñada mayoritariamente por la mujer.

El capítulo número veintisiete, titulado: El magisterio como profesión cargada de connotaciones sociales. cuya autora Dña. Cynthia Ramos Boudrias, refleja que "el Magisterio es una de las profesiones más feminizadas que existen. El $66,7 \%$ de todo el profesorado español es femenino. Este desequilibrio no es fruto de la casualidad y menos en un ámbito laboral en el que las mujeres no han tenido nada fácil su inserción como consecuencia de los roles sociales asociados a su género".

Una profesión tradicionalmente masculina, como es la ingeniería agrícola, donde el número de mujeres aun es escaso se plasma en el capítulo veintiocho, titulado: La paz y la tranquilidad que se respira lejos del mundanal ruido. La mujer en la Ingeniera Técnica Agrícola. Cuya autora Dña. Azahara Calderón Laguna, relata experiencias profesionales y el amor que tiene a su profesión y al desempeño de ésta, además del duro camino laboral en situaciones de inclemencias climatológicas y otras cuestiones laborales difíciles de controlar para los agricultores.

El capítulo número veintinueve, titulado: La participación de la mujer en el trabajo agrícola. Agricultora / Propietaria y/o jornalera, de las autoras Dña. María Elena Nieto-Cabrera y la Dra. Concepcion NietoMorales, que mediante entrevistas a profesionales reflejan la realidad de ser agricultoras y jornaleras agrícolas en España.

El trabajo de la mujer en el medio ambiente ocupa el capítulo treinta, titulado: La profesionalización del estudio y cuidado del medio ambiente. Mujer y medio ambiente, cuya autora Dña. Ana María González Cabrera, donde expone una dura realidad laboral que no permite conciliar vida laboral y ser madre, poniendo de manifestó las dificultades que ha vivido para poder trabajar y tener un hijo.

Es poco frecuente encontrar una mujer torera en una plaza de toros y se refleja en el capítulo treinta y uno, titulado: Los toros: Cultura, Arte y Tradición. La Valentía y el arte de lidiar toros profesionalmente por una Mujer. María Paz Vega Jiménez. España, es un capítulo realizado mediante una entrevista a Dña. María Paz Vega, una mujer torera y que ha triunfado en este difícil mundo del toro. Las autoras son Dña. M. Elena Nieto-Cabrera y la Dra. Concepcion Nieto-Morales.

El capítulo treinta y dos cuya autora es Dña. María José Villegas Navas y titulado Arbitrando partidos de futbol. Pasado y Presente. Una 
profesión desarrollada casi exclusivamente por hombres, y nos cuenta la autora que afortunadamente la mentalidad va cambiando y se va valorando el trabajo de la mujer en la profesión.

También hay mujeres que a pesar de contar con formación universitaria deciden dedicarse a cuidar a la familia y este hecho se encuentra en el capítulo treinta y tres, titulado: La belleza de la familia, cuya autora es Dña. Ester López Fernández. La autora analiza como la mujer en el hogar construyendo una familia también contribuye al desarrollo de la sociedad. El capítulo treinta y cuatro, titulado: ¿Necesito una empleada de hogar? La gran aportación social del Servicio Doméstico. cuyas autoras Dña. María Elena Nieto-Cabrera y la Dra. Concepcion Nieto-Morales, han deseado poner en valor el trabajo y la aportación social de la mujer que desempeña su trabajo como empleada en el servicio doméstico. El capítulo se ha realizado mediante varias entrevistas a trabajadoras del servicio doméstico.

No todas las mujeres trabajan en el entorno donde han nacido y criado, también ha contribuido a esta obra en el capítulo treinta y cinco, titulado: Desarrollo y promoción de la mujer africana: La mujer misionera al servicio del cambio social, cuya autora la Dra. M. Josefa Vázquez Fernández, a través de una entrevista relata la vida de la religiosa Sor Bernarda García Castellano, se trata de una mujer de 70 años, con estudios de Grado superior en Administración, que tomó los votos como religiosa en la congregación salesiana de las Hijas de María Auxiliadora el cinco de agosto de 1974. El pasado año de 2019, recibió por parte de Manos Unidas el Premio Caminando Juntos, dentro de los Premios 60 Aniversario con los que se galardonó a destacadas figuras e instituciones. Sus palabras la definen: "Mi camino durante treinta y dos años en las misiones en el África del oeste lo llamo "camino de providencia, presencia de Dios en mi vida".

El capítulo número treinta y seis, titulado: La inserción laboral de mujeres que han llegado a estar presas cumpliendo condena privativa de libertad. Delincuencia femenina. Cuyas autoras, Dña. María Elena Nieto-Cabrera, Dña. Inés María Martínez Cramer y la Dra. Concepcion Nieto-Morales, ha tratado de reflejar la trayectoria laboral de la mujer que en algún momento de su vida ha estado privada de libertad. Suele ser una vida muy dura en todos los aspectos de la misma.

El libro también consta de una Reflexión a Modo de Conclusión, cuya autora la Dra. Concepcion Nieto-Morales, realiza una valoración final del libro y además refleja parte de su trayectoria laboral y las vicisitudes que ha tenido en su trayectoria formativa, laboral, tanto en la administración como en los quince años de trabajo en la universidad. 